\title{
Preparation of pore gradient silicon nitride ceramics by a high- velocity oxy-fuel spraying technique
}

\author{
Fei CHEN, ${ }^{\dagger}$ Qiang SHEN, Julie M. SCHOENUNG* and Lianmeng ZHANG
}

State Key Lab of Advanced Technology for Materials Synthesis and Processing, Wuhan University of Technology, Wuhan 430070, China

*Department of Chemical Engineering and Materials Science, University of California Davis, CA 95616, USA

\begin{abstract}
The preparation of pore gradient silicon nitride $\left(\mathrm{Si}_{3} \mathrm{~N}_{4}\right)$ ceramics was investigated by thermally spraying dense $\mathrm{Si}_{3} \mathrm{~N}_{4}$ coatings onto the porous $\mathrm{Si}_{3} \mathrm{~N}_{4}$ ceramic substrates via a high-velocity oxyfuel (HVOF) spraying method. Spray powders with excellent processability were developed and produced by spray drying and sintering in a nitrogen atmosphere. After sieving, the powders with average particle size of $45-75 \mu \mathrm{m}$ were selected. Optimization of spray parameters such as spray distance and hydrogen flow rate was carried out in order to find the most decisive factor necessary for the production of dense and welladhering coatings and pore gradient stuctures. Zirconium phosphate bonded $\mathrm{Si}_{3} \mathrm{~N}_{4}$ porous ceramics were used as the substrate and coatings were obtained only when spray distance was $200 \mathrm{~mm}$. A pore gradient structure was obtained at lower $\mathrm{H}_{2}$ flow rate, while poor-adhering coatings were obtained at higher $\mathrm{H}_{2}$ flow rate due to the etching. The hardness is significantly improved after $\mathrm{Si}_{3} \mathrm{~N}_{4}$ coatings were successfully applied.
\end{abstract}

(C)2009 The Ceramic Society of Japan. All rights reserved.

Key-words : Silicon nitride, Pore gradient, High-velocity oxyfuel (HVOF), Spraying

[Received December 1, 2008; Accepted February 19, 2009]

\section{Introduction}

Pore gradient structure ceramics, as one of the special functionally graded materials (FGM), has been investigated for years because of their superior mechanical and thermal properties, and potential aerospace applications. ${ }^{1)}$ In particular, several fabrication processes such as ceramic/carbon mixtures, ${ }^{1)}$ packing ceramic powders to varying densities followed by partial sintering $^{2)}$ and tape casting ${ }^{3)}$ techniques have been explored to prepare pore gradient ceramics. As a high temperature ceramic, silicon nitride $\left(\mathrm{Si}_{3} \mathrm{~N}_{4}\right)$ ceramic is used in numerous applications because of its high-temperature strength, good oxidation resistance and low thermal expansion coefficient. ${ }^{4), 5)}$ Nowadays, various processing techniques have been developed to prepare both porous and dense $\mathrm{Si}_{3} \mathrm{~N}_{4}$ ceramics for structural and functional applications. ${ }^{6), 7)}$ However, little effort has focused on pore gradient structure $\mathrm{Si}_{3} \mathrm{~N}_{4}$ ceramics which may be used in heat insulation applications. Our previous work reported on the preparation of pore gradient $\mathrm{Si}_{3} \mathrm{~N}_{4}$ ceramics by using the spark plasma sintering (SPS) method, involving the packing of the porous and dense $\mathrm{Si}_{3} \mathrm{~N}_{4}$ ceramics separately and the SPS sintering thereafter. ${ }^{8)}$

Thermal spray processes like plasma spray have demonstrated the potential in producing graded deposits, where researchers have used twin powder feed systems to mix different proportions of powders. ${ }^{9)}$ FGMs vary in composition and/or microstructure from one boundary (substrate) to another (top service surface). HVOF (High Velocity Oxy-Fuel) ${ }^{10), 11)}$ is a thermal spray with extremely high spray temperature and velocity that makes it possible for preparing dense ceramic coatings and for the spray powders to penetrate into the porous substrate. Figure 1(a) shows a schematic illustration of the HVOF system we used in this study. The HVOF system can be operated with hydrogen, propane, propylene and

Corresponding author: F. Chen; E-mail: chenfei027@gmail.com ethene as fuel gases. During spraying, fuel and oxygen are fed into the chamber. The powder is injected axially into the combustion area and accelerated through a convex-concave nozzle because of a hot high pressure flame. Spray distance, fuel-to-oxygen flow rate and fuel gas category are considered to be the three most important factors that influence the coating quality. For example, when spray distance is decreased and fuel-to-oxygen flow rate is increased, the particle velocity, temperature and impact energy will be increased. As a result, coatings with reduced porosity and enhanced mechanical properties will be obtained. Compared with the other processes shown in Fig. 1(b) HVOF has the particle temperature ranging from $1400-2000^{\circ} \mathrm{C}$, and particle velocity of $\sim 500 \mathrm{~m} / \mathrm{s}^{12}$ ) Because $\mathrm{Si}_{3} \mathrm{~N}_{4}$ does not melt, but decomposes at temperatures exceeding $1900^{\circ} \mathrm{C}$, the HVOF process is ideal for the spray of $\mathrm{Si}_{3} \mathrm{~N}_{4}$, which is considered to be a nonsprayable material.

The most successful attempt to prepare $\mathrm{Si}_{3} \mathrm{~N}_{4}$-based coatings thus far was made by Sodeoka et al. ${ }^{13)}$ using powders obtained from $\beta$ '-SiAlON $\left(\mathrm{Si}_{6-z} \mathrm{Al}_{z} \mathrm{O}_{z} \mathrm{~N}_{8-z}\right)$ with different degrees of substitution, $z$. The initial powders, including $\mathrm{Si}_{3} \mathrm{~N}_{4}, \mathrm{Al}_{2} \mathrm{O}_{3}$ and $\mathrm{AlN}$ with different ratios to achieve $\beta^{\prime}$-SiAlON with different $\mathrm{z}$ values, were fired at $1600^{\circ} \mathrm{C}$ for $2 \mathrm{~h}$ before spray. The powder was then used to deposit coatings by atmospheric plasma spraying (APS) with $\mathrm{Ar} / \mathrm{H}_{2}$ or $\mathrm{Ar} / \mathrm{H}_{2} / \mathrm{N}_{2}$ as plasma gases, with the maximum $z=4$ in all classes and with $z=3$ at higher plasma power. The reference also mentioned that no coatings could be obtained from powders with low degrees of substitution $(z=1-2)$. However, when the degree of substitution is too high, e.g., $z>2$, the $\mathrm{Si}_{3} \mathrm{~N}_{4}$ content is less than 70 mass\%. The presence of the other elements in the material may severely influence the properties of the material. So, it is significant to explore a proper way to spray $\mathrm{Si}_{3} \mathrm{~N}_{4}$ ceramic with high $\mathrm{Si}_{3} \mathrm{~N}_{4}$ content.

In this paper, $\mathrm{SiAlON}$ powder, including $\mathrm{Si}_{3} \mathrm{~N}_{4}, \mathrm{Al}_{2} \mathrm{O}_{3}$ and $\mathrm{AlN}$ powders, together with $\mathrm{Y}_{2} \mathrm{O}_{3}$ powder, which is the most effective additive for $\mathrm{Si}_{3} \mathrm{~N}_{4}$ sintering, was used as the initial powders. $\beta^{\prime}$ - 


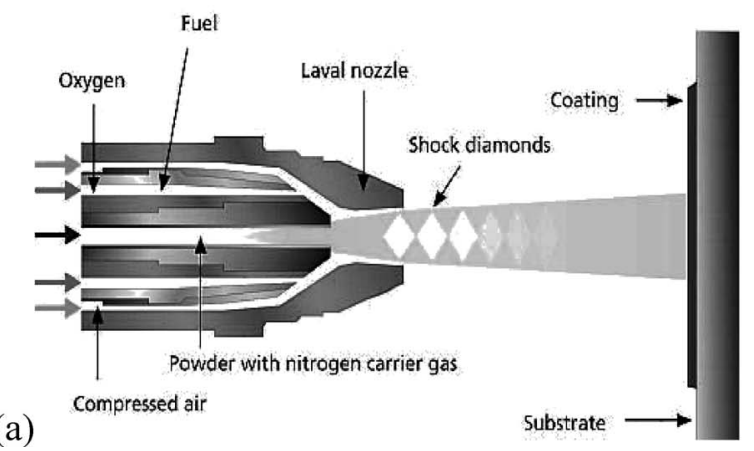

(b)

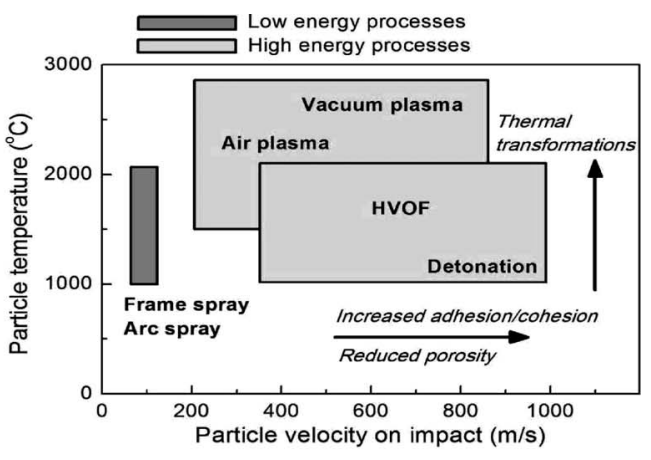

Fig. 1. (a) Schematic illustration of the HVOF system from http://www.fst.nl; (b) particle velocity and temperature among different spray processes.

Table 1. Chemical Composition of $\beta$-SiAlON Raw Material

\begin{tabular}{ccc}
\hline Powder & Compositions, mass $\%$ & $z$ in $\mathrm{Si}_{6-z} \mathrm{Al}_{2} \mathrm{O}_{z} \mathrm{~N}_{8-z}$ \\
\hline$\beta$-SiAlON & $90 \mathrm{Si}_{3} \mathrm{~N}_{4}, 3 \mathrm{Al}_{2} \mathrm{O}_{3}, 6 \mathrm{Y}_{2} \mathrm{O}_{3}, 1 \mathrm{AlN}$ & 1 \\
\hline
\end{tabular}

SiAlON powder with very low $z$ value was synthesized then as the spray powder. $\mathrm{Si}_{3} \mathrm{~N}_{4}$ matrix coatings were sprayed via $\mathrm{HVOF}$ and the effect of spray parameters such as spray distance and fuel-to-oxygen ratio on the structure and properties of the coatings was investigated.

\section{Experimental procedure}

\subsection{Raw materials}

$\beta$-SiAlON raw powder was prepared by mixing of the individual commercially available $\mathrm{Si}_{3} \mathrm{~N}_{4}, \mathrm{Al}_{2} \mathrm{O}_{3}$, and $\mathrm{AlN}$ powders, while $\mathrm{Y}_{2} \mathrm{O}_{3}$ powder was used as a sintering aid, was added by agglomeration (spray dring). This powder was produced by International Syalons Newcastle Limited, England. The raw powder characteristics are shown in Table $\mathbf{1}$.

\subsection{Spray powder preparation}

The raw $\beta$-Sialon powder was put into an $\mathrm{Al}_{2} \mathrm{O}_{3}$ crucible, and then sintered in a tube furnace at $1600^{\circ} \mathrm{C}$ for $2 \mathrm{~h}$ in pure $\mathrm{N}_{2}$ at a flow rate of $50 \mathrm{sccm}$ as a reaction and carrier gas, subsequently mechanically treated by a mild milling process, and finally fractionized by sieving. In accordance with the other successful experimental results, ${ }^{14)}$ the spray powder with the particle size of $45-75 \mu \mathrm{m}$ was used.

\subsection{HVOF spray process}

HVOF spray experiments were performed with a Top Gun (gas) system, using facilities at Plasma Technology Inc. (PTI), Torrance, CA, USA. The HVOF deposition conditions are listed in Table 2. Only hydrogen gas was used as the fuel gas. The spray distance and $\mathrm{H}_{2}$ flow rate were changed in order to optimize the spray parameters as shown in Table 2. The $30 \mathrm{~mm}$ $\mathrm{ZrP}_{2} \mathrm{O}_{7}$ bonded $\mathrm{Si}_{3} \mathrm{~N}_{4}$ porous ceramics reported in Ref. ${ }^{6}$ ) with porosity of $\sim 40 \%$ were used as the substrate material. The HVOF spray process is clearly shown in Fig. 2.

\subsection{Characterization}

The phase compositions were analyzed by X-ray diffraction (XRD) using a Rigaku-D/Max-IIIA diffractometer operated at 45 $\mathrm{kV}$ and $40 \mathrm{~mA}$. Copper $(\mathrm{Cu})$ radiation was used. The microstructures of both the spray powders and coatings were observed by scanning electron microscopy (SEM; JSM-5610LV, Japan). The
Table 2. HVOF Spray Conditions

\begin{tabular}{lcccc}
\multicolumn{1}{c}{ Sample } & 1 & 2 & 3 & 4 \\
\hline Spray distance $(\mathrm{mm})$ & 200 & 200 & 300 & 300 \\
$\mathrm{H}_{2}$ flow rate $(1 / \mathrm{min})$ & 600 & 700 & 600 & 700 \\
$\mathrm{O}_{2}$ flow rate $(1 / \mathrm{min})$ & \multicolumn{4}{c}{350} \\
Substrate cooling & \multicolumn{5}{c}{ Air jet } \\
Carrier gas & \multicolumn{5}{c}{$\mathrm{N}_{2}$} \\
Combustion gas & $\mathrm{O}_{2}+\mathrm{H}_{2}$
\end{tabular}

Powder feed rate $(\mathrm{g} / \mathrm{min})$

Substrate Temp.

60

Spray passes

$100-300^{\circ} \mathrm{C}$

40

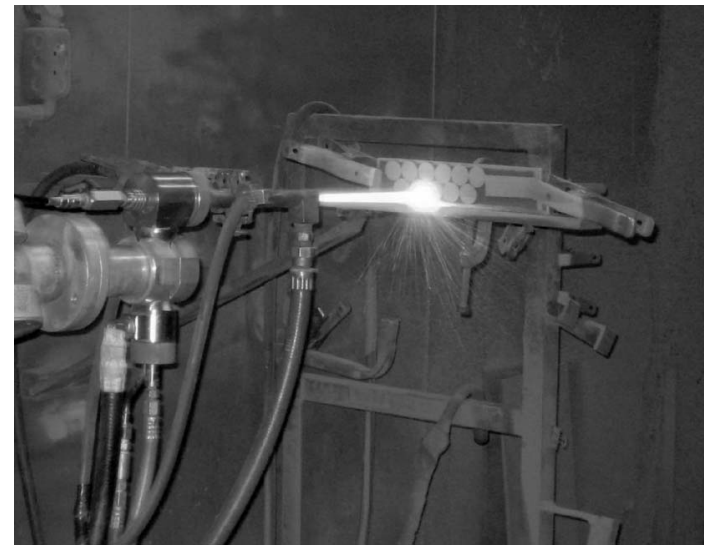

Fig. 2. HVOF spray experimental process at PTI.

amount of porosity was determined by image analysis. Microhardness testing was performed using a Vickers microhardness tester, with an indentation load of $50 \mathrm{~g}$ and 10 measurements for each sample.

\section{Results and discussion}

\subsection{Structure and properties of spray powders}

The morphology of the spray powder particles is shown in Fig. 3(a). It is seen that the spray powders are made up of agglomerate particles with the size of $45-75 \mu \mathrm{m}$. The agglomerates have porous structure composed of small crystals $<200 \mathrm{~nm}$ in size. The X-ray diffraction patterns of the raw material mixture, the 


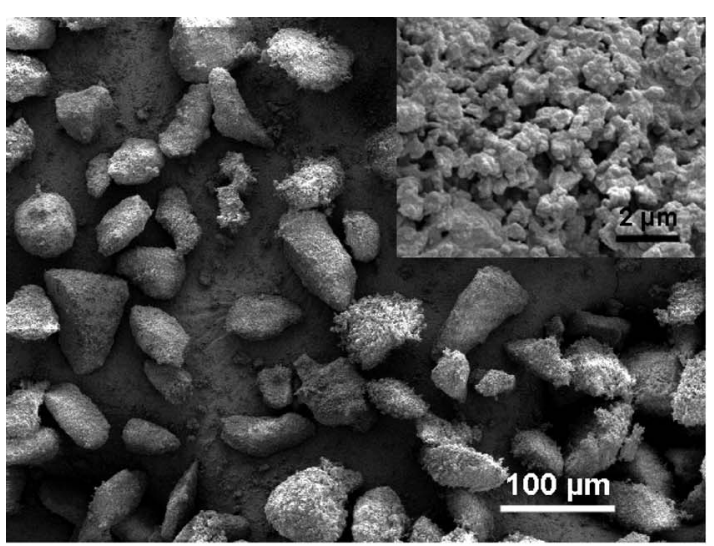

(a)

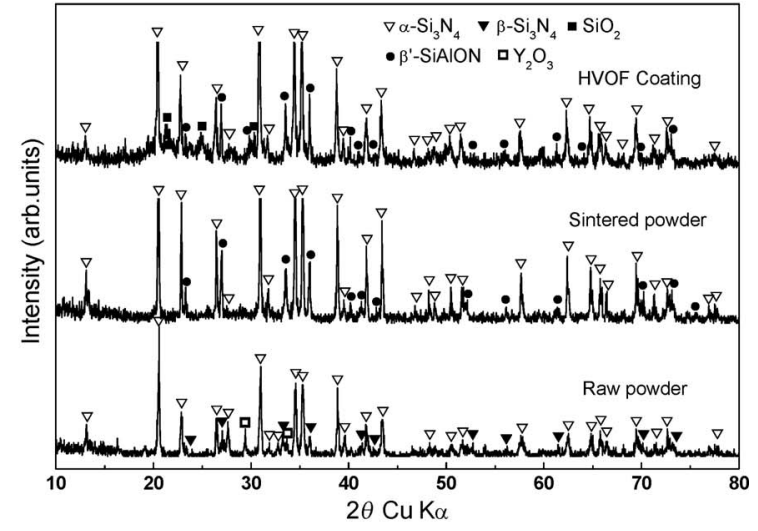

(b)

Fig. 3. (a) Morphology of the spray powder, the inset highlights the surface of the particle; (b) X-ray diffraction patterns of raw material, synthesized spray powder and the HVOF sprayed coating.

synthesized spray powder, and the sprayed coating are shown in Fig. 3(b). Comparing with the raw powder composite, which consists of $\alpha-\mathrm{Si}_{3} \mathrm{~N}_{4}, \beta-\mathrm{Si}_{3} \mathrm{~N}_{4}$ and $\mathrm{Y}_{2} \mathrm{O}_{3}$ phases, the spray powder synthesized after sintering at $1600^{\circ} \mathrm{C}$ consists of $\alpha-\mathrm{Si}_{3} \mathrm{~N}_{4}$ and $\beta^{\prime}-$ SiAlON phases. During sintering of the spray powder, partial phase transformation of $\alpha-\mathrm{Si}_{3} \mathrm{~N}_{4}$ to $\beta-\mathrm{Si}_{3} \mathrm{~N}_{4}$ takes place by solution and reprecipitation processes. The porous powder structure shown in Fig. 3(a) is believed to be the reason for the incomplete transformation from $\mathrm{Si}_{3} \mathrm{~N}_{4}$ to $\beta^{\prime}$-SiAlON. The sprayed HVOF coating also consists of $\alpha$ - $\mathrm{Si}_{3} \mathrm{~N}_{4}, \beta^{\prime}$-SiAlON and a small amount of $\mathrm{SiO}_{2}$ phases, which illustrates that oxidation during the HVOF process is quite limited.

\subsection{Effect of spray parameters on the structure and hardness of the coatings}

For all spray samples listed in Table 2, only samples 1 and 2 were found to be coated with $\mathrm{Si}_{3} \mathrm{~N}_{4}$ coatings. No coatings were observed on samples 3 and 4 . So, the spray distance played a more significant role in the formation of $\mathrm{Si}_{3} \mathrm{~N}_{4}$ ceramic coatings than the fuel flow rate. In the HVOF process, the spray distance is a practical method of controlling the amount of energy the powder has at impact. The shorter the spray distance, the higher the particle velocity and particle impact force on the surface. The other effect of spray distance is the temperature of the deposit. The longer the particle takes to reach the substrate, the more heat it loses to the atmosphere, and the less thermal energy it has to transfer to the substrate. Consequently, the spray distance of 300 $\mathrm{mm}$ may cause a severe heat loss and the spray distance of 200 $\mathrm{mm}$ was the prerequisite for formation of $\mathrm{Si}_{3} \mathrm{~N}_{4}$ ceramic coatings.

The SEM images for samples 1 and 2 are shown in Fig. 4. It is shown clearly that a pore gradient structure is obtained in sample 1, with the lower $\mathrm{H}_{2}$ flow rate. From the pore distribution analysis shown in Fig. 4 (a), the relatively dense (with porosity $<5 \%$ ) $\mathrm{Si}_{3} \mathrm{~N}_{4}$ coating is $\sim 50 \mu \mathrm{m}$ in thickness, followed by a pore gradient area $(\sim 100 \mu \mathrm{m}$ thick). The area with porosity of $\sim 30 \%$ is the porous $\mathrm{Si}_{3} \mathrm{~N}_{4}$ substrate. It is also observed that the coating and the substrate are well bonded by the pore gradient area and no cracks are generated during spraying. From the SEM image of the coating surface shown in the right of Fig. 4 (a), the elongated $\beta$ '-SiAlON grains are clearly seen with an average grain size of $\sim 2 \mu \mathrm{m}$. For sample 2, with higher $\mathrm{H}_{2}$ flow rate, no obvious pore gradient area is observed both the SEM image and the image

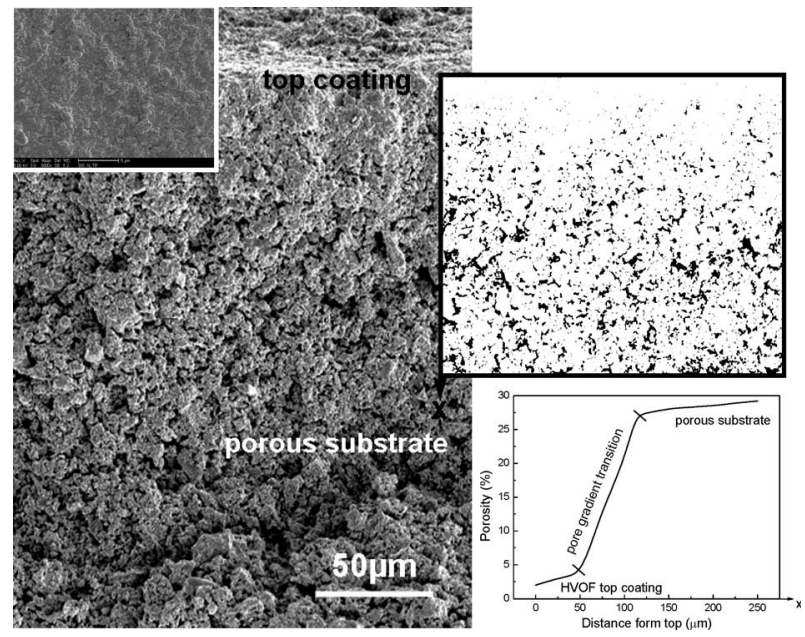

(a)

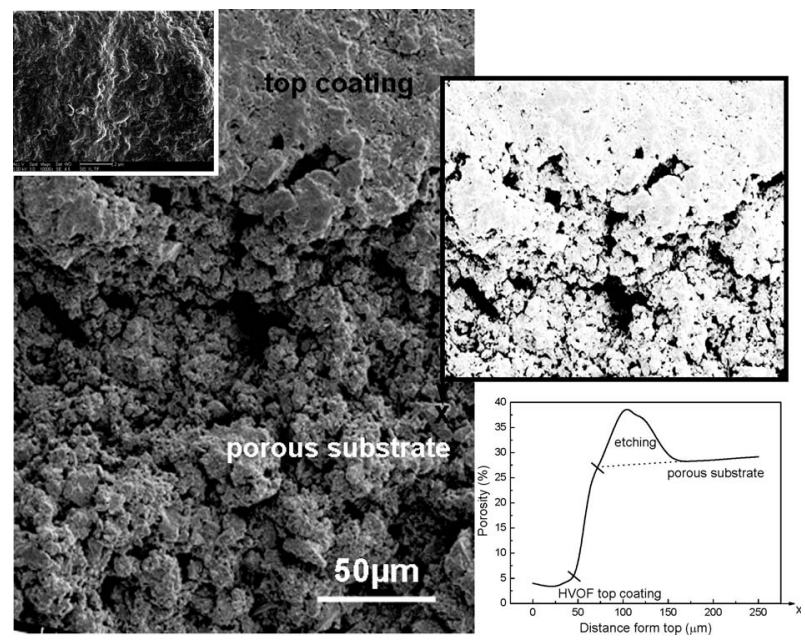

(b)

Fig. 4. (a) SEM image for cross section of sample 1 (left), the pore distribution image and curve are obtained by image analysis, and the coating surface morphology image (inset); (b) SEM image for cross section of sample 2 (left), the pore distribution image and curve, and the coating surface morphology image (inset). 
Table 3. Porosity and Microhardness of Sprayed Coatings

\begin{tabular}{ccccc}
\hline \multirow{2}{*}{ Sample } & \multirow{2}{*}{$\begin{array}{c}\text { Porosity, } \\
\%\end{array}$} & $\begin{array}{c}\text { Microhardness, } \\
\text { GPa }\end{array}$ & \multicolumn{2}{c}{ Spray conditions } \\
\cline { 4 - 5 } & & & $\mathrm{H}_{2}$-to- $\mathrm{O}_{2}$ Ratio & Spray distance \\
\hline 1 & 3 & 3.8 & 1.67 & 200 \\
2 & 5 & 3.5 & 2 & 200 \\
3 & 28 & 2.5 & 1.67 & 300 \\
4 & 25 & 2.3 & 2 & 300 \\
\hline
\end{tabular}

analysis results. The coating is also $\sim 50 \mu \mathrm{m}$ in thickness and the relative density is higher than $95 \%$. There is an area with relatively high porosity between the coating and the substrate, which is believed to result from an etching phenonmenon during the HVOF process due to the high powder velocity and temperature caused by the higher $\mathrm{H}_{2}$ flow rate. It is known that the amount of thermal energy (enthalpy heat content) transferred from the flame to the powder varies depending on the fuel flow rate and oxygen flows. ${ }^{15)}$ As the $\mathrm{H}_{2}$-to- $\mathrm{O}_{2}$ ratio is increased, by increasing the $\mathrm{H}_{2}$ flow rate, more thermal energy is transferred to the powder. Thus the particle temperature and velocity are increased with the $\mathrm{H}_{2}$-to- $\mathrm{O}_{2}$ ratio. From the surface image of the coating, the apparent powder melting phenomenon is also observed.

The Vickers microhardness values for the HVOF spray samples are shown in Table 3. The hardness increases as apparent porosity decreases. It is also shown that samples 3 and 4 have almost the same porosity with the porous substrate material, indicating the failure to form dense $\mathrm{Si}_{3} \mathrm{~N}_{4}$ coatings. For samples 1 and 2, the hardness is significantly improved after $\mathrm{Si}_{3} \mathrm{~N}_{4}$ coatings were successfully sprayed. The maximum hardness, is about 3.8 $\mathrm{GPa}$, is still significantly lower than that for sintered $\mathrm{Si}_{3} \mathrm{~N}_{4}$ ceramics. ${ }^{16)}$

\section{Conclusions}

Thermal spraying of $\mathrm{Si}_{3} \mathrm{~N}_{4}$ with $\beta$ '-SiAlON $(z=1)$ phase by using HVOF was attempted. Coatings were obtained only when spray distance was $200 \mathrm{~mm}$. A pore gradient structure was obtained at lower $\mathrm{H}_{2}$ flow rate, while poor-adhering coatings were obtained at higher $\mathrm{H}_{2}$ flow rate due to the etching caused by the high particle velocity and temperature. The hardness is significantly improved after $\mathrm{Si}_{3} \mathrm{~N}_{4}$ coatings were successfully applied.

Acknowledgments Financial support has been provided by the U.S Office of Naval Research, through Grant N00014-08-1-0569, and the Program for New Century Excellent Talents in University of P. R. China, through Grant NCET-05-0661. We would also like to thank Darryl Mack for technical assistance. The $\beta$-SiAlON powder was provided free-of-charge by Nick Fecitt in International Syalons Newcastle Ltd., England.

\section{References}

1) K. Maca, P. Dobsak and A. R. Boccaccini, Ceram. Int., 27, 577-584 (2001).

2) S. F. Corbin, X. Zhao-jie, H. Henein and P. S. Apte, Mater. Sci. Eng. A, 262, 192-203 (1999).

3) R. Jedamzik, A. Neubrand and J. Roedel, J. Am. Ceram. Soc., 83, 983-985 (2000).

4) A. J. Pyzik and D. R. Beaman, J. Am. Ceram. Soc., 76, 2737-2744 (1993).

5) C. J. Lee and D. J. Kim, J. Am. Ceram. Soc., 82, 753-756 (1999).

6) F. Chen, Q. Shen, F. Q. Yan and L. M. Zhang, Mater. Sci. Technol., 22, 915-918 (2006).

7) F. L. Riley, J. Am. Ceram. Soc., 83, 245-265 (2000).

8) L. M. Zhang, F. Chen, Q. Shen and F. Q. Yan, "Multiscale and Functionally Graded Materials 2006," Ed. by G. H. Paulino et al. (2008) pp. 3-9.

9) K. A. Khor, Y. W. Gu and Z. L. Dong, J. Therm. Spray Technol., 9, 245-249 (2000).

10) T. A. Dobbins, R. Knight and M. J. Mayo, J. Therm. Spray Technol., 12, 214-225 (2003).

11) S. Usuba and R. B. Heimann, J. Therm. Spray Technol., 15, 356-363 (2006).

12) X. Provot, "Proceedings of the National Thermal Spray Conference", Ed. by C. C. Berndt, Anaheim, USA (1993) pp. 159-163.

13) S. Sodeoka, K. Ueno, Y. Hagiwara and S. Kose, J. Therm. Spray Technol., 1, 153-159 (1992).

14) S. Thiele, L.-M. Berger, M. Herrmann, M. Nebelung, R. B. Heimann, T. Schnick, B. Wielage, P. Vuoristo and T. Schnick, J. Therm. Spray Technol., 11, 218-225 (2002).

15) E. Lugscheider, C. Herbst and L. Zhao, Sur. Coat. Technol., 108-109, 16-23 (1998).

16) R. W. Rice, C. C. Wu and F. Borchelt, J. Am. Ceram. Soc., 77, 2539-2553 (1994). 